\title{
PENGARUH ABDOMINAL MUSCLE STRENGTHENING DENGAN METODE PILATES
}

\author{
Bambang Trisnowiyanto \\ Jurusan Fisioterapi Politeknik Kesehatan Kemenkes.R.I. Surakarta \\ Email: trisnowiyanto@yahoo.co.id
}

\begin{abstract}
Effect of Abdominal Muscle Strengthening with Pilates. Someone who has a habit of doing passive activities such as prolonged sitting at work can increase the risk of muscle power imbalance in the muscles supporting the body that ultimately is experiencing pain in the lower back, so that when doing activities or work that exceeds the physical capacity owned, will prone to fatigue and injury can occur if imposed, such as the occurrence of spasm or cramps in the abdominal muscles. The increase in abdominal muscle strength, one of which can be achieved with Pilates exercise which has the advantage of having a focus exercise aimed strengthen core stability muscles include the abdominal muscles. This study was to determine the effect of Pilates exercises to increase the strength of the abdominal muscles. Total subjects were 34 people consisting of mothers of households with an age range between 30-50 years. This research method was experiment with the design of one group pre-post test with control with inclusion and exclusion criteria. Preferred forms of Pilates exercise was a special movement that aimed to exercise the abdominal muscles as much as 16 movement, exercise programs were given for 2 months, with a duration of 45 minutes/ session, 2 times/ week. Measurement of abdominal muscle strength were used curl up test. The differences test of Pre-post test with Wilcoxon Test, was obtained $\mathrm{p}=0.000(\mathrm{p}<0.05)$ and the differences test of pre-pre-test and post-post test with MannWhitney U Test both groups $\mathrm{p}=0.849(\mathrm{p}<0.05)$ and post-post test both groups $\mathrm{p}=0.007(\mathrm{p}<0.05)$. It can be concluded that Pilates exercises affect the increase in abdominal muscle strength.
\end{abstract}

Keywords: Pilates exercises, Abdominal muscle strength

\begin{abstract}
Abstrak: Pengaruh Abdominal Muscle Strengthening dengan Metode Pilates. Seseorang yang memiliki kebiasaan melakukan aktivitas pasif seperti duduk lama saat bekerja dapat meningkatkan resiko terjadinya muscle power imbalance pada otot-otot penyangga tubuh yang pada akhirnya mudah mengalami nyeri pada punggung bagian bawah, sehinga bila melakukan aktifitas atau pekerjaan yang melebihi kapasitas fisik yang dimiliki, akan mudah mengalami kelelahan dan bila dipaksakan dapat terjadi cedera, seperti terjadinya spasme atau kram pada otot perut. Peningkatan kekuatan otot perut, salah satunya dapat dicapai dengan latihan Pilates yang memiliki keunggulan memiliki fokus latihan yang bertujuan menguatkan otot-otot core stability diantaranya adalah otot perut. Tujuan: Untuk mengetahui pengaruh latihan Pilates terhadap peningkatan kekuatan otot perut. Subyek Penelitian Sebanyak 34 terdiri dari ibu-ibu rumah tangga dengan rentang usia antara 30-50 tahun. Metode Penelitian: Eksperimen dengan rancangan one group pre-post test with control dengan kriteria inklusi dan ekslusi. Bentuk latihan pilates yang dipilih adalah khusus gerakan yang ditujukan untuk latihan otot-otot perut sebanyak 16 gerakan, program latihan diberikan selama 2 bulan, dengan durasi selama 45 menit/sesi latihan, 2 kali/minggu. Pengukuran kekuatan otot perut menggunakan curl up test. Analisis Statistik: Uji beda pre-post test dengan Wilcoxon Test, didapatkan $\mathrm{p}=0,000(p<0.05)$ dan uji beda pre-pre test dan post-post test dengan Mann-whitney U Test kedua kelompok $\mathrm{p}=0,849(p<0.05)$ dan post-post test kedua kelompok $p=0,007$ ( $p<0.05)$. Kesimpulan: Latihan Pilates berpengaruh terhadap peningkatan kekuatan otot perut.
\end{abstract}

Kata kunci: Latihan pilates, Kekuatan otot perut

Kekuatan otot perut adalah kemampuan otot perut untuk berkontraksi berulang kali tanpa mengalami kelelahan dengan mudah (Alters \& Schiff, 2013). Kekuatan otot perut merupakan salah satu komponen kebugaran jasmani yang penting dalam melakukan aktivitas sehari-hari.

Dalam kehidupan sehari-hari, otot perut bersama dengan otot lain yang saling berhubungan dalam core berfungsi dalam mempertahankan posisi organ dalam, menjaga postur tubuh, ataupun aktivitas fungsional seperti angkat angkut, duduk, berdiri, berjalan dan berlari, melompat serta berbagai bentuk gerak. Dengan daya tahan otot yang memadai seseorang dapat melakukan aktivitas dengan waktu yang 
lebih lama dan tidak mudah mengalami kelelahan (Cole \& Seabourne, 2003).

Kemampuan daya tahan dan kekuatan otot perut seseorang dipengaruhi oleh tipe serabut otot, jenis kelamin, umur, nutrisi, dan kekuatan otot (Naternicola, 2015; Hoeger dan Hoeger, 2015).

Seseorang yang memiliki kebiasaan melakukan aktivitas pasif seperti duduk lama saat bekerja atau saat sedang menonton televisi dapat meningkatkan resiko terjadinya nyeri punggung bawah. Hal ini dikarenakan dengan posisi duduk terlalu lama atau lebih dari 2 jam dapat melemahkan otot perut, pelvic tilting ke depan, dan meningkatkan kurva lordosis lumbal.

Saat ini, 90\% kasus nyeri punggung bawah bukan disebabkan oleh kelainan organik, melainkan oleh kesalahan posisi tubuh dalam bekerja (Llewellyn, 2006 dikutip oleh Pratiwi, dkk., 2009). Salah satu penyebab cedera dan nyeri pada punggung bawah adalah akibat menurunnya daya tahan otot perut. Seseorang yang memiliki otot perut lemah melakukan aktifitas/pekerjaan yang lebih dari kapasitas fisik yang dimiliki dapat menimbulkan kelelahan dan bila beban kerja terlalu berat dipaksakan dapat terjadi cedera, seperti kram otot perut.

Hal ini sering terjadi saat seseorang berlari atau jalan dengan intensitas berlebih dapat mengalami kram otot perut (Bergeron, 2008). Hal ini kemungkinan besar disebabkan oleh daya tahan otot perut terhadap aktifitas yang kurang, sehingga menimbulkan adanya cedera. Cedera disebabkan kurangnya pengetahuan tentang latihan dan penambahan beban secara tepat, sikap tubuh yang salah ketika mengangkat beban, ketidakoptimalan keseimbangan tubuh, kelemahan otot perut (Sukarmin, 2005, dikutip oleh Yuliana, dkk., 2014).

Peningkatan kekuatan otot perut dapat dicapai dengan beberapa latihan, antara lain: senam aerobik, calisthetic, pilates, excersice ball, resistennce bands dan yoga. (Fichera, 2008; Hoffman, 2006). Dari beberapa latihan di atas, latihan pilates memiliki keunggulan memiliki fokus latihan yang bertujuan menguatkan otototot core stability salah satunya otot perut (Sekendiz, 2007). Pada latihan pilates ditujukan pada latihan pada core stability terutama otot fleksor dan otot ekstensor punggung bawah guna meningkatkan stabilitas tubuh dan membuat seluruh badan menjadi lebih mudah bergerak.

Gaya Latihan pilates terbagi menjadi dua yaitu gaya tradisional di mana latihan menggunakan beberapa rangkaian dalam beberapa set dengan pengulangan sesuai kondisi individu dan gaya modern yang lebih menekankan pada penyesuaian pengenalan diri dan meningkatkan kesadaran dengan jalan latihan pada kebutuhan masing-masing klien, kelemahan dan penguatan (Sekendiz, 2007).

Otot perut merupakan salah satu otot yang penting dalam core stability, karena pada dinding otot perut terdiri dari beberapa otot yang memiliki arah yang berbeda-beda yang dapat memperkuat core. Sedangkan fungsi utama otot perut adalah gerakan fleksi trunk (Saladin, 2012). Dinding otot perut terdiri dari beberapa otot, antara lain: (1) Obliqus abdominis eksternus, (2) Obliqus abdominis internus, (3) Tranversus abdominis, (4) Rectus abdominis.

Pada penelitian Sekendiz (2007) dan Kloubec (2010) terdapat peningkatan signifikan pada kekuatan otot perut dari subyek diberi perlakuan latihan Pilates. Akan tetapi diperlukan penelitian lebih lanjut mengenai metode Pilates yang tepat untuk masyarakat Indonesia.

\section{METODE PENELITIAN}

Metode penelitian ini adalah eksperimen kuasi dengan rancangan one group pre-post test with control. Kriteria inklusi untuk subjek pada penelitian ini adalah (1) perempuan, (2) umur antara 30-50 tahun. (3) sehat dan tidak sedang menderita nyeri pada area perut. Sedang kriteria eksklusinya adalah: (1) memiliki aktivitas berolahraga yang rutin, (2) subjek tidak mampu berdiri maupun berjalan, Kriteria drop out diberlakukan bila: (1) tidak mengikuti latihan minimal 3 kali berturut-turut, (2) subjek mendapatkan interverensi latihan lain diluar program penelitian. Pengukuran daya tahan otot perut dilakukan sebelum perlakuan dan setelah perlakuan selama 8 minggu dengan frekuensi 2 kali seminggu dan durasi latihan selama 50 menit pada setiap sesi latihannya.

Alat ukur yang digunakan untuk mengukur kekuatan otot perut adalah curl up test test (partial sit up test dan crunch test). Validitas dan reabilitas alat ukur ini test retest $\mathrm{r}=0,98$, intertester $\mathrm{r}=0,76$ (Diener, et al, 1995). Tes ini menggunakan alat berupa kertas pembatas dengan lebar 3,5 inci $(8,89 \mathrm{~cm})$ dan panjang 30 inci $(76,2 \mathrm{~cm})$, timer dengan jam tangan/ stopwatch dan pengujian dilakukan pada lantai yang datar.

Prosedur pengukuran curl up test: (1) subyek pada posisi terlentang, lutut ditekuk, kaki rata pada lantai, kedua lengan lurus menempel pada paha, jari diluruskan dan kepala menyentuh lantai dan pastikan kaki subyek berjarak tidak terlalu dekat dengan pantat, telapak kaki masih 
rata dengan lantai, (2) setelah subyek siap pada posisi yang benar, kertas pembatas berada di bawah kaki dan sangat dekat dengan ujung jari yang istirahat, lalu pengukur bersiap-siap menghitung dan menghentikan bila terjadi kesalahan, (3) jaga agar tumit tetap menyentuh lantai. Subyek melakukan curl up dengan cara mengangkat kepala dan bahu secara perlahan dengan jarak dagu dengan dada $\pm 5 \mathrm{~cm}$, tangan bergerak melewati kertas pembatas, lalu kembali ke posisi semula. (4) pengulangan dilakukan perlahan dengan irama 1 curl selama 3 detik dilakukan sebanyak mungkin. Penilaian berupa banyaknya curl up yang dilakukan. Tes dihentikan apabila sudah dilakukan 75 curl up.

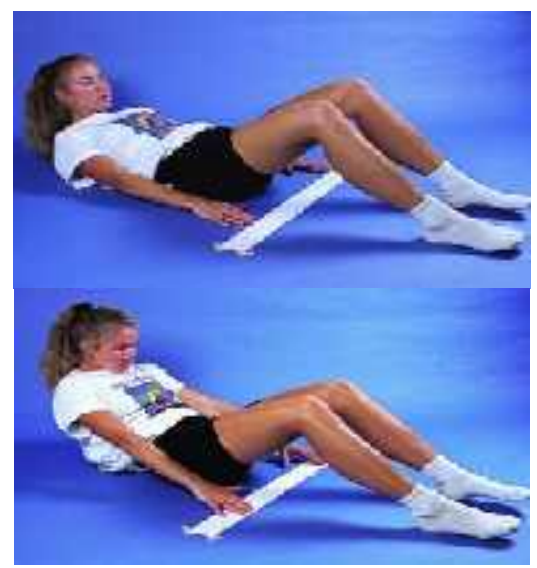

Gambar 1. Curl up test (Hoffman, 2006)

Variabel penelitian dalam penelitian ini adalah program latihan penguatan otot perut metode Pilates dan daya tahan otot perut.

\section{HASIL}

Hasil analisis dari penelitian ini dijelaskan sebagai berikut, kelompok I memiliki rerata usia 43 sedangkan pada kelompok II rerata usia 38,59 tahun. Sehingga dapat disimpulkan karakteristik subjek berdasarkan usia didapatkan hasil rerata usia pada kedua kelompok relatif seimbang.

Tabel 1. Karakteristik Subjek Penelitian berdasarkan Usia

\begin{tabular}{lll}
\hline Statistik & Kelompok I & Kelompok II \\
\hline Minimum & 35 & 30 \\
Maksimum & 50 & 50 \\
Rata-rata & 43 & 38,59 \\
Standar Deviasi & 5,374 & 6,145 \\
\hline
\end{tabular}

Keadaan awal hasil curl up test, sebelum perlakuan didapatkan hasil rerata 19,94 pada kelompok I dan 20,29 pada kelompok II. Sehingga dapat disimpulkan bahwa rerata kedua kelompok sebelum perlakuan relatif sama.
Tabel 2. Sebaran Data Nilai Curl Up Test Sebelum Perlakuan

\begin{tabular}{lrr}
\hline Karakteristik & Kelompok I & Kelompok II \\
\hline - Minimum & 9 & 10 \\
- Maksimum & 39 & 41 \\
- Rata-rata & 19,94 & 20,29 \\
- Standar Deviasi & 8,422 & 9,681 \\
\hline
\end{tabular}

Keadaan akhir hasil curl up test setelah perlakuan didapatkan hasil rerata 31,71 pada kelompok I dan 20,41 pada kelompok II Sehingga dapat disimpulkan terdapat perbedaan rerata kekuatan otot perut.

Tabel 3. Sebaran Data Nilai Curl Up Test Setelah Perlakuan

\begin{tabular}{lrr}
\hline Karakteristik & Kelompok I & Kelompok II \\
\hline - Minimum & 15 & 10 \\
- Maksimum & 52 & 35 \\
- Rata-rata & 31,71 & 20,41 \\
- Standar Deviasi & 10,987 & 9,448 \\
\hline
\end{tabular}

Selisih hasil curl up test awal dan akhir, pada kelompok I terdapat perbedaan rerata pada awal dan akhir pengukuran curl up test yakni rerata awal 19,94 kali dan rerata akhir 31,71 kali sehingga dihasilkan selisih 11,77 kali, sedangkan pada kelompok II terdapat rerata awal dan akhir relatif sama pada pengukuran curl up test, yakni rerata awal 20,29 kali dan rerata akhir 20,41 kali sehingga didapatkan selisih 0,12 kali.

\begin{tabular}{|c|c|c|c|c|c|c|}
\hline \multirow[b]{2}{*}{ Statistik } & \multicolumn{3}{|c|}{ Kelompok perlakuan } & \multicolumn{3}{|c|}{ Kelompok kontrol } \\
\hline & $\begin{array}{c}C U T \\
\text { awal } \\
\text { I }\end{array}$ & $\begin{array}{c}C U T \\
\text { akhir I }\end{array}$ & Selisih & $\begin{array}{c}C U T \\
\text { awal } \\
\text { II }\end{array}$ & $\begin{array}{c}C U T \\
\text { akhir } \\
\text { II }\end{array}$ & Selisih \\
\hline Minimum & 9 & 15 & 6 & 10 & 10 & 0 \\
\hline Maksimum & 39 & 52 & 13 & 41 & 35 & -6 \\
\hline Rata-rata & 19,94 & 31,71 & 11,77 & 20,29 & 20,41 & 0,12 \\
\hline $\begin{array}{l}\text { Standar } \\
\text { deviasi }\end{array}$ & 8,422 & 10,987 & 2,565 & 9,681 & 9,448 & -233 \\
\hline
\end{tabular}

Pada penelitian ini jumlah subjek masing-masing kelompok 17 orang, sehingga tidak dilakukan uji normalitas data dan dianggap data berdistribusi tidak normal karena subjek kurang dari 30. Dengan demikian uji yang digunakan adalah uji non parametrik dengan wilcoxon dan mann-whitney. Hasil analisis wilcoxon diperoleh $p=0,000 \quad(p<0,05)$ pada kelompok I. Hal ini menunjukkan terdapat pengaruh latihan penguatan otot perut metode Pilates terhadap daya tahan otot perut diterima.

Uji mann-whitney didapatkan hasil $p=0,007 \quad(p<0,05)$. yang berarti terdapat perbedaan antara kelompok perlakuan dan 
kontrol. Uji beda pre-pre test kelompok perlakuan dan kelompok control dengan mannwhitney didapat hasil sebesar $\mathrm{p}=0,849(\mathrm{p}>0,05)$, maka dapat disimpulkan bahwa data berangkat dari data yang homogen sehingga perubahan peningkatan kekuatan otot perut benar-benar dari efek perlakuan .

\section{PEMBAHASAN}

Latihan penguatan otot perut metode Pilates berpengaruh terhadap peningkatan kekuatan dan daya tahan otot perut karena latihan Pilates memiliki fokus pada latihan penguatan dan stretching pada otot-otot penegak tubuh pada punggung, perut dan pantat untuk membangun penyanggaan tubuh yang kuat saat digunakan menggerakkan seluruh tubuh (Hoffman, 2006). Latihan pilates menggunakan metode berupa variasi latihan otot perut yang dilakukan secara rutin. Otot-otot core dilatih dengan berbagai variasi gerakan yang secara teori mampu memberikan hasil terbaik untuk meningkatkan kekuatan dan daya tahan (Kloubec, 2011). Hal ini sesuai dengan penelitian Sekendiz (2007) yang mengatakan latihan pilates didapatkan hasil terdapat peningkatan signifikan pada daya tahan otot perut setelah latihan Pilates. Penelitian lain menunjukkan hasil sejalan, terdapat peningkatan kekuatan otot perut setelah dilakukan latihan Pilates dilakukan oleh Kloubec (2010).

Berdasarkan teori latihan menurut Brignell (2004), latihan yang dilakukan dengan pengulangan dan kontrol berupa pemanjangan

\section{DAFTAR PUSTAKA,}

Alters, S., Schiff, W. 2013. Essential Concepts for Healthy Living. $6^{\text {th }}$ ed, Jones and Barnett Learning, United States of America, hal 350.

Bergeron,M. F. 2008. Muscle Cramps during Excersice Is It Fatigue or Electrolyte Deficit?. Curr. J. Sport. Med. Rep, vol. 7, no. 4, hal. S50-S55.

Brignell, R. 2004. The Pilates Handbook: A Young Woman's Guide to Health and Well-Being. New York: The Rosen Publishing Groub Inc. hal. 23-41.

Cole, S., Seabourne, T. 2003. Athletic Abs: Maximum Core Fitness Training; Human Kinetics. United State of America, hal. 814. durasi dari latihan sebelumnya latihan Pilates yang berfokus pada penguatan dan dilakukan pengulangan menggunakan beban level sedang dapat meningkatkan kekuatan otot (Salo \& Riewald, 2008). Latihan penguatan dengan pengulangan dapat mempengaruhi serabut otot tipe I slow twitch yang dimiliki. Serabut saraf ini menggunakan oksigen lebih baik dan juga menyediakan lebih banyak simpanan energi untuk digunakan saat latihan dalam periode yang cukup lama, seperti berlari, berenang, mendaki gunung dan lain-lain. Serabut ini dapat menahan kelelahan dan menanggapi latihan yang menggunakan beban ringan dan pengulangan tinggi. Satu faktor lain yang mempengaruhi daya tahan otot adalah serabut otot tipe IIa yang merupakan kombinasi dari serabut otot slowtwitch dan fast-twitch. Otot yang memiliki karakteristik slow-twitch atau fast-twitch dipengaruhi oleh desain latihannya. Jika latihan menggunakan beban berat dengan pengulangan rendah, maka serabut otot tipe fast-twitch akan aktif. Jika latihan menggunakan beban ringan dan pengulangan tinggi, maka yang aktif adalah serabut otot tipe slow-twitch. Serabut otot tipe I dan IIa teraktivasi menyebabkan kemampuan kekuatan dan daya tahan otot dalam menjalankan aktivitas meningkat (Naternicola, 2015).

\section{SIMPULAN}

Terdapat pengaruh latihan Pilates terhadap peningkatan kekuatan otot perut.

Diener, M. H., Golding, L. A., Diener, D. 1995. Validity and Realibility of a one minute half sit up test of abdominal strength and endurance. Sport Med Train Rehab, vol. 6, pp. 105-119.

Fichera, S. 2008. Stop Aging, Start Training: Look and Feel Twenty Years Younger. United States of America: Basic Health Publications Inc., hal. 21-29.

Hoeger, W., Hoeger, S. 2015. Chapter Muscular Strength and Endurance dalam Principles and Labs for Physical Fitness. California: Cengage Learning, hal 242-253.

Hoffman, J. 2006. Norms for Fitness, Performance, and Health. United State of America: Human Kinetic, hal. 41, 106107. 
Kloubec, J. A. 2010. Pilates for improvement of muscle endurance, flexibility,balance, and posture. J Strength Con Res, 2, hal. 661-7.

Kloubec, J. 2011. Pilates: how does it work and who need it?. Muscle. Ligaments. Tendons. $J$, vol.1, 2, hal.61-66.

Llewellyn, V. 2006. Back and Neck RelatedCondition: Low Back Pain. www.plymouthphysio.co.uk (Diakses pada tanggal12/06/2015).

Naternicola, N. 2015. Fitness: Steps to Success Activity Series. Human Kinetics. New Zealand, hal. 42-65.

Saladin, K. S. 2012. Anatomy \& Physiology: The Unity Of Form And Function. New York
McGraw-Hill Companies, Rev. ed, hal. 335-336.

Salo, D., Riewald, S. A. 2008. Complete Conditioning for Swimming. Human Kinetics. United State. hal. 84-85.

Sekendiz B, Altun O, Korkusuz F, Akın S.2007. Effects of Pilatesexercise on trunkstrength, endurance and flexibility in sedentaryadult females. JBodyMovTher, no. 11, hal 31826.

Yuliana, S., Adiatmika, I. P., Irfan, M., Al Hazmi, D. F. 2014. Pelatihan Kombinasi Core Stability Exersice dan Ankle Strategy Exercise Tidak Lebih Meningkatkan Keseimbangan Statis Pada Mahasiswa S1 Fisioterapi. 